\title{
Galileo millimeter-level kinematic precise point positioning with ambiguity resolution
}

\author{
Georgia Katsigianni $i^{1,2^{*}} \mathbb{D}$, Felix Perosanz ${ }^{1}$, Sylvain Loyer ${ }^{2}$ and Mini Gupta ${ }^{3}$
}

\begin{abstract}
On February 11, 2019, four additional Galileo satellites were put into service, approaching the completion of the European global navigation satellite system constellation. For the first time, the performance of Galileo system in terms of high-accuracy precise point positioning (PPP) can be evaluated. The results presented in this paper are based on one full week (February 11-17, 2019) of post-processed kinematic positioning for a set of fixed stations at a 30-s sampling. Due to the availability of precise Galileo orbit and "integer" clock products, delivered by CNES/CLS Analysis Center of International GNSS Service, the impact of Galileo ambiguity resolution on the positioning results is also quantified. The precision using Galileo-only measurements in the East, North and Up directions is $10 \mathrm{~mm}, 7 \mathrm{~mm}$ and $33 \mathrm{~mm}$ for PPP and $6 \mathrm{~mm}, 5 \mathrm{~mm}$ and $28 \mathrm{~mm}$ for PPP-AR (PPP with ambiguity resolution) (1 sigma), respectively. These results shall represent the future performance of the Galileo system for kinematic post-positioning. They also indicate the important future contribution of Galileo to high-accuracy multi-GNSS applications.
\end{abstract}

Keywords: Galileo, Precise point positioning, Ambiguity resolution, Integer precise point positioning, Kinematic, Post-processing

\section{Introduction}

The International GNSS Service (IGS) gives an open access to the highest quality of GPS and GLONASS data and products (Dow et al. 2009). The development of new global navigation satellite system (GNSS), such as the European Galileo, the Chinese Beidou, made it clear that the new era of multi-GNSS is forthcoming. Consequently, the IGS has started a pilot project called multi-GNSS Experiment (MGEX) (IGS 2011). Since then, MGEX started delivering the best possible multi-GNSS products available to the users (Montenbruck et al. 2017). Various so-called analysis centers (AC) participate in this effort, using a global network of GNSS stations. It has been demonstrated by Xia et al. (2018) and Li et al. (2018) that including Galileo observations in a global multiGNSS processing is feasible for PPP-AR.

On February 11, 2019, four additional Galileo satellites were put into service. At that moment, the Galileo space

\footnotetext{
*Correspondence: georgia.katsigianni@cnes.fr

${ }^{1}$ Centre National d'Etudes Spatiales (CNES), 18 Avenue Edouard Belin,

31400 Toulouse, France

Full list of author information is available at the end of the article
}

segment consisted of 22 usable satellites ( 8 in plane A, 7 in plane $B$ and 7 in plane $C$ ) and 2 satellites in elliptical orbits that drift relatively to the 3 nominal planes (GSA 2019). The satellite distribution within the constellation allows for the first time to evaluate the performance of the Galileo system that is approaching an optimal configuration.

In this study, we focus on the so-called precise point positioning (PPP) technique (Zumberge et al. 1997). In contrast to differential positioning, which eliminates common measurement biases between the stations and the user, the PPP approach consists in considering corrections for each individual measurement bias; thus, no control station around is needed. The PPP technique can provide positioning accuracy of sub-decimeter or even sub-centimeter level using the already fully deployed GPS and/or GLONASS systems. The final accuracy depends on individual terms compositing the observation model like satellite position, clock offsets, atmospheric delays, phase center offsets, phase center variations or phase windup effect (Kouba 2009). Nevertheless, the ultimate PPP performance is reached only when the integer number of phase observations between a receiver and a given satellite can be identified. This so-called undifferenced ambiguity 
resolution step is challenging, but its feasibility has been demonstrated using GPS data (Laurichesse et al. 2009). Recently, Katsigianni et al (2018a, b) and Li et al. (2018) have shown that such method can be applied to Galileo data. As a consequence, for the first time and from this time onward, Galileo-only kinematic (post-processed) solutions using PPP and PPP with ambiguity resolution (PPP-AR) can be computed with nearly full constellation.

This publication is organized in the following sections. Firstly, the undifferenced ambiguity resolution and PPP-AR processing are briefly presented. "Experimentation and analysis of the results" section is devoted to the experiments, the processing and the results. Finally, in "Summary, conclusions and perspectives" section, some conclusions are given together with suggestions for further work and perspectives.

\section{Galileo PPP with ambiguity resolution}

The phase measurements transmitted by Galileo satellites give the distance to the receiver with a mm-level noise, but they are biased by satellite and receiver electronic delays and by an integer number of phase cycles called phase ambiguity. Resolving these biases is a key issue to access the ultimate precision of the so-called IPPP (integer-PPP) or PPP-AR (PPP with ambiguity resolution) technique. One possible approach called "integer recovery clock" consists in using a consistent and dedicated set of satellite clock offsets and satellite hardware biases (Geng et al. 2010). In October 2018, the CNES/CLS IGS Analysis Centre started providing post-processed "integer" Galileo satellite clock offsets associated with Galileo "wide-lane satellite biases" hardware delays (Katsigianni et al. 2018a, b; Perosanz et al. 2018; Loyer et al. 2018). These products are used in the following analysis.

A direct comparison of pseudorange and phase measurements cannot identify reliably the correct integer ambiguity bias. The main reasons are the pseudorange noise level compared to the phase wavelength and the opposite sign of the ionosphere delays affecting the two measurements. Therefore, a two-step procedure based on different combinations of pseudorange and phase measurements is needed.

In the first step, the following Melbourne-Wübbena (MW) (Melbourne 1985; Wübbena 1985) equation for Galileo pseudorange from code $\left(P_{E 1}\right.$ and $P_{E 5 a}$ in $\left.[\mathrm{m}]\right)$ and carrier phase ( $L_{E 1}$ and $L_{E 5 a}$ in [m]) is used:

$$
\begin{aligned}
\mathrm{MW}= & \left(\frac{f_{E 1}}{f_{E 1}-f_{E 5 a}} L_{E 1}-\frac{f_{E 5 a}}{f_{E 1}-f_{E 5 a}} L_{E 5 a}\right) \\
& -\left(\frac{f_{E 1}}{f_{E 1}+f_{E 5 a}} P_{E 1}+\frac{f_{E 5 a}}{f_{E 1}+f_{E 5 a}} P_{E 5 a}\right) \\
= & \lambda_{\mathrm{WL}}\left(L_{E 1}-L_{E 5 a}\right)-\lambda_{\mathrm{NL}}\left(P_{E 1} / \lambda_{E 1}+P_{E 5 a} / \lambda_{E 5 a}\right)
\end{aligned}
$$

where $f_{E 1}$ and $f_{E 5 a}$ are the Galileo frequencies $E 1$ $(1575.420 \mathrm{MHz})$ and $E 5 a(1176.450 \mathrm{MHz}), \lambda_{E 1}$ and $\lambda_{E 5 a}$ are the respective wavelengths (in [m]), $\lambda_{\mathrm{WL}}=c /\left(f_{E 1}-f_{E 5 a}\right)=0.751 \mathrm{~m}$ is the wide-lane wavelength, $\lambda_{\mathrm{NL}}=c /\left(f_{E 1}+f_{E 5 a}\right)=0.109 \mathrm{~m}$ is the narrowlane wavelength, and $c$ represents the speed of light (in $[\mathrm{m} / \mathrm{s}]$ ). It has been proven (Katsigianni et al. 2018a, b) that the following equations are valid for Galileo:

$$
\tilde{N}_{\mathrm{WL}}=\left(N_{E 1}-N_{E 5 a}\right)+\mu_{r}-\mu^{\mathrm{s}}
$$

where $\tilde{N}_{\text {WL }}$ is the averaged values of wide-lane ambiguities over one pass, $N$ is the ambiguity term for the corresponding frequency, $\mu^{\mathrm{s}}$ is the satellite delay (also known in the bibliography as WL satellite bias-WSB), and $\mu_{r}$ is the receiver delay (also known as WL receiver biasWRB) (both are in [WL wavelength units]).

It has been confirmed that $\mu^{\mathrm{s}}$ are stable and constant for Galileo over long periods. Hence, values are stable unless a change is observed (Katsigianni et al. 2018a, b). The values of $\mu^{\mathrm{s}}$ and their stability over a period of 2 years are shown in Fig. 1.

The $\mu_{r}$ can be estimated at each epoch (when at least two satellites are visible). The WL ambiguities are solved as real numbers, using a least squares estimation (LSE) system of equations. The float ambiguities are fixed to integer values by applying a bootstrap method (Blewitt 1989; Dong and Bock 1989).

The next step is to form an ionosphere-free linear combination for code and carrier phase measurements (Loyer et al. 2012):

$$
\begin{aligned}
& \frac{\gamma P_{E 1}-P_{E 5 a}}{\gamma-1}=\frac{\gamma D_{\mathrm{PE} 1}-D_{\mathrm{PE} 5 a}}{\gamma-1}+\Delta h_{P} \\
& \frac{\gamma \lambda_{E 1} L_{E 1}-\lambda_{E 5 a} L_{E 5 a}-\lambda_{E 5 a} \tilde{N}_{\mathrm{WL}}}{\gamma-1} \\
& \quad=\frac{\gamma D_{\mathrm{LE} 1}-D_{\mathrm{LE} 5 a}}{\gamma-1}+\lambda_{\mathrm{NL}} W+\Delta h_{\mathrm{L}}+\lambda_{\mathrm{NL}} N_{E 1}
\end{aligned}
$$

where $\gamma=\lambda_{E 5 a}^{2} / \lambda_{E 1}^{2}=f_{E 1}^{2} / f_{E 5 a}^{2}, \Delta h_{P}$ and $\Delta h_{L}$ are ionosphere-free phase clock differences for code and carrier phase measurements [extensive explanation in Loyer et al. (2012)], $D_{P E 1}, D_{P E 5 a}, D_{L E 1}$ and $D_{L E 5 a}$ are the geometrical propagation distances between the satellite and the receiver for each type of measurement including tropospheric elongation, relativistic effects, etc., and $W$ is the phase windup effect (in [cycles]).

The system of equations can be solved using the GRM (name for MGEX contribution of the CNES/CLS IGS Analysis Center) satellite orbit and clock products. The GRM clock products are the so-called integer recovery 


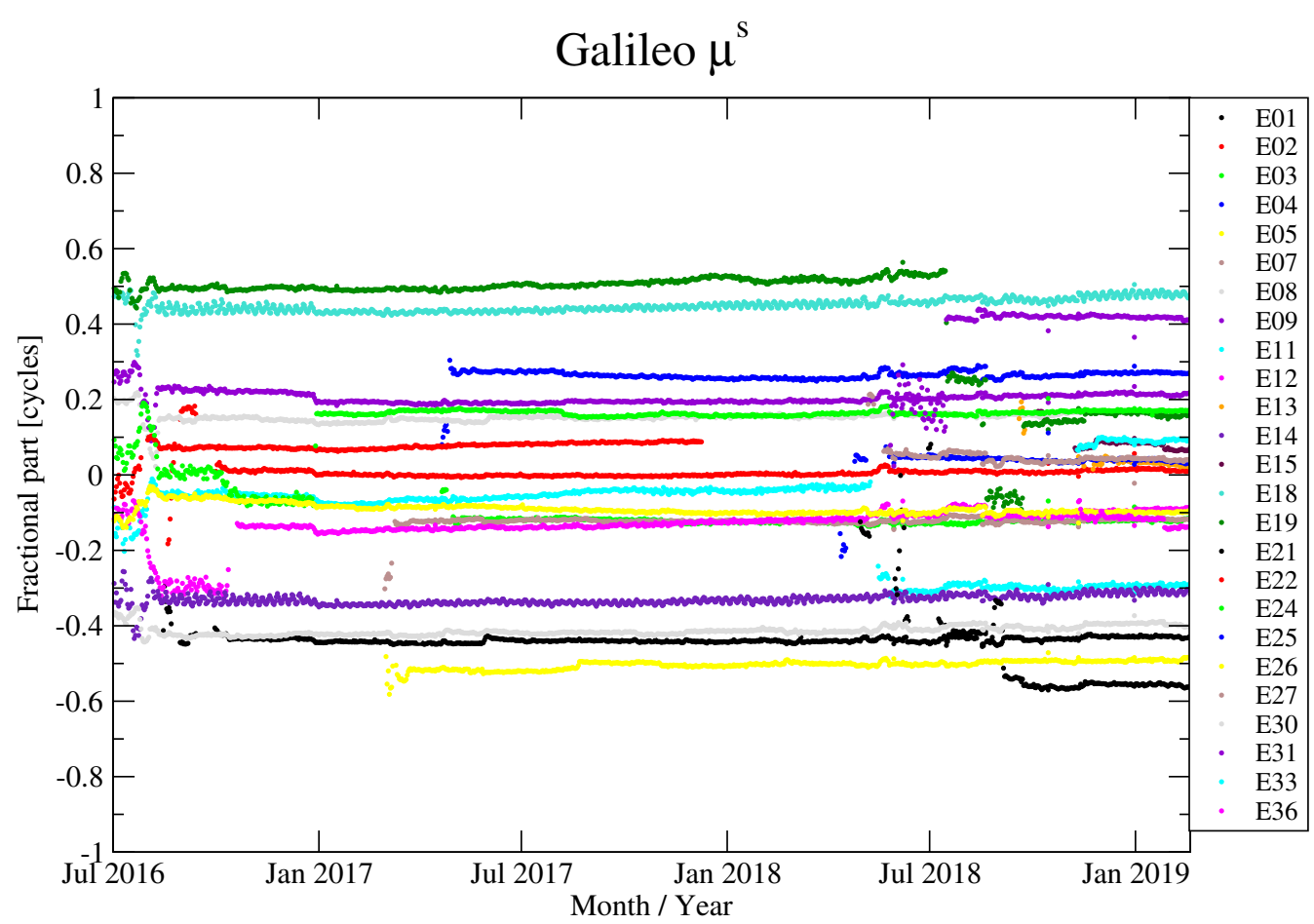

Fig. 1 Fractional part of $\mu^{5}$ values for Galileo

clocks (IRCs) method (Geng et al. 2010) which preserves the integer nature of phase ambiguity biases (Loyer et al. 2012). The first result of the LSE system of equations gives a PPP solution in which ambiguity parameters are resolved as real values.

Then, the integer ambiguity resolution is taking place by applying a bootstrap method (Blewitt 1989; Dong and Bock 1989). Each $N_{E 1}$ (integer number of NL cycles) parameter satisfying covariance criteria is sequentially fixed to an integer value. At this point only ionospherefree ambiguity-fixed phase measurements are kept. The system of equations is again solved to give the PPP-AR solution.

An extended overview of the entire process for PPP and PPP-AR procedure is given in Fund et al. (2013), Petit et al. (2015) and Montenbruck et al. (2018).

Table 1 Ambiguity fixing rates for every day of the year (DOY)

\begin{tabular}{llllllll}
\hline DOY & $\mathbf{0 4 2}$ & $\mathbf{0 4 3}$ & $\mathbf{0 4 4}$ & $\mathbf{0 4 5}$ & $\mathbf{0 4 6}$ & $\mathbf{0 4 7}$ & $\mathbf{0 4 8}$ \\
\hline BRUX (\%) & 90.42 & 100 & 100 & 100 & 100 & 100 & 95.12 \\
KOUG (\%) & 91.67 & 100 & 100 & 100 & 96.30 & 100 & 92 \\
AREG (\%) & 93.10 & 93.75 & 96.97 & 97.87 & 96.77 & 96.67 & 88.57 \\
KIRU (\%) & 90.38 & 98.04 & 98.00 & 98.08 & 100 & 97.87 & 93.62 \\
\hline
\end{tabular}

Table 2 Precision in East, North and Up directions for PPP and PPP-AR

\begin{tabular}{|c|c|c|c|c|c|c|c|}
\hline \multirow{2}{*}{$\begin{array}{l}\text { Mode } \\
\text { Direction }\end{array}$} & \multicolumn{3}{|l|}{ PPP } & \multicolumn{3}{|l|}{ PPP-AR } & \multirow[t]{2}{*}{ Station clock } \\
\hline & East $(\mathrm{mm})$ & North (mm) & $\mathrm{Up}(\mathrm{mm})$ & East (mm) & North (mm) & $U p(m m)$ & \\
\hline BRUX & 10 & 7 & 33 & 6 & 5 & 28 & External maser \\
\hline KOUG & 10 & 10 & 38 & 9 & 8 & 36 & Internal \\
\hline AREG & 13 & 9 & 30 & 10 & 8 & 34 & External rubidium \\
\hline KIRU & 9 & 8 & 19 & 5 & 6 & 17 & External cesium \\
\hline
\end{tabular}




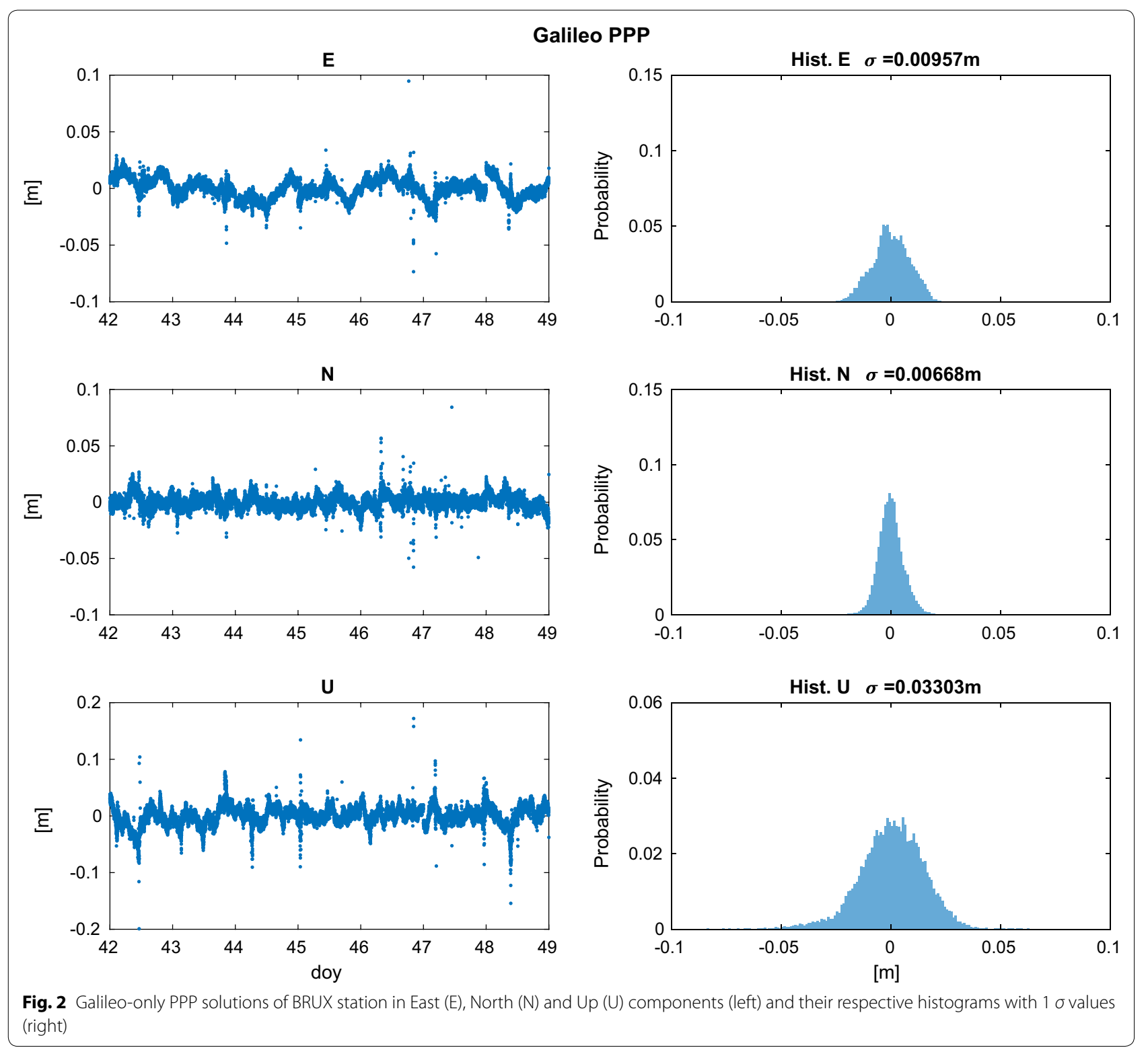

\section{Experimentation and analysis of the results}

Using a fixed point and checking the repeatability of its independent epoch per epoch positioning solutions is the easiest way to evaluate the data, the processing strategy (i.e., models used) and the software used. Post-processing of the data benefits from better orbit corrections and from better decorrelation of the parameters to be resolved using a global resolution (e.g., least squares) instead of a sequential filter (e.g., Kalman).

We processed Galileo-only PPP and PPP-AR solutions using the state-of-the-art of models and conventions recommended by the IERS and the IGS. However, phase center variation maps of ground geodetic antennas of the E5 signals are still not available to the users.
We used the one of the L2 bands instead, which may degrade the solutions by few millimeters. In addition to the receiver position estimation for every $30 \mathrm{~s}$, integer phase ambiguities, zenith tropospheric delays and horizontal gradients as well as receiver clock biases were estimated. A set of four IGS stations is used. For the period of study, 1 week of data (February 11-17, 2019) are chosen. During that period, 24 Galileo satellites (including the ecliptic E14 and E18) were processed.

For the PPP-AR solutions, the ambiguity fixing rates are given in Table 1.

The results in East, North and Up directions are given in Table 2 for each mode. 


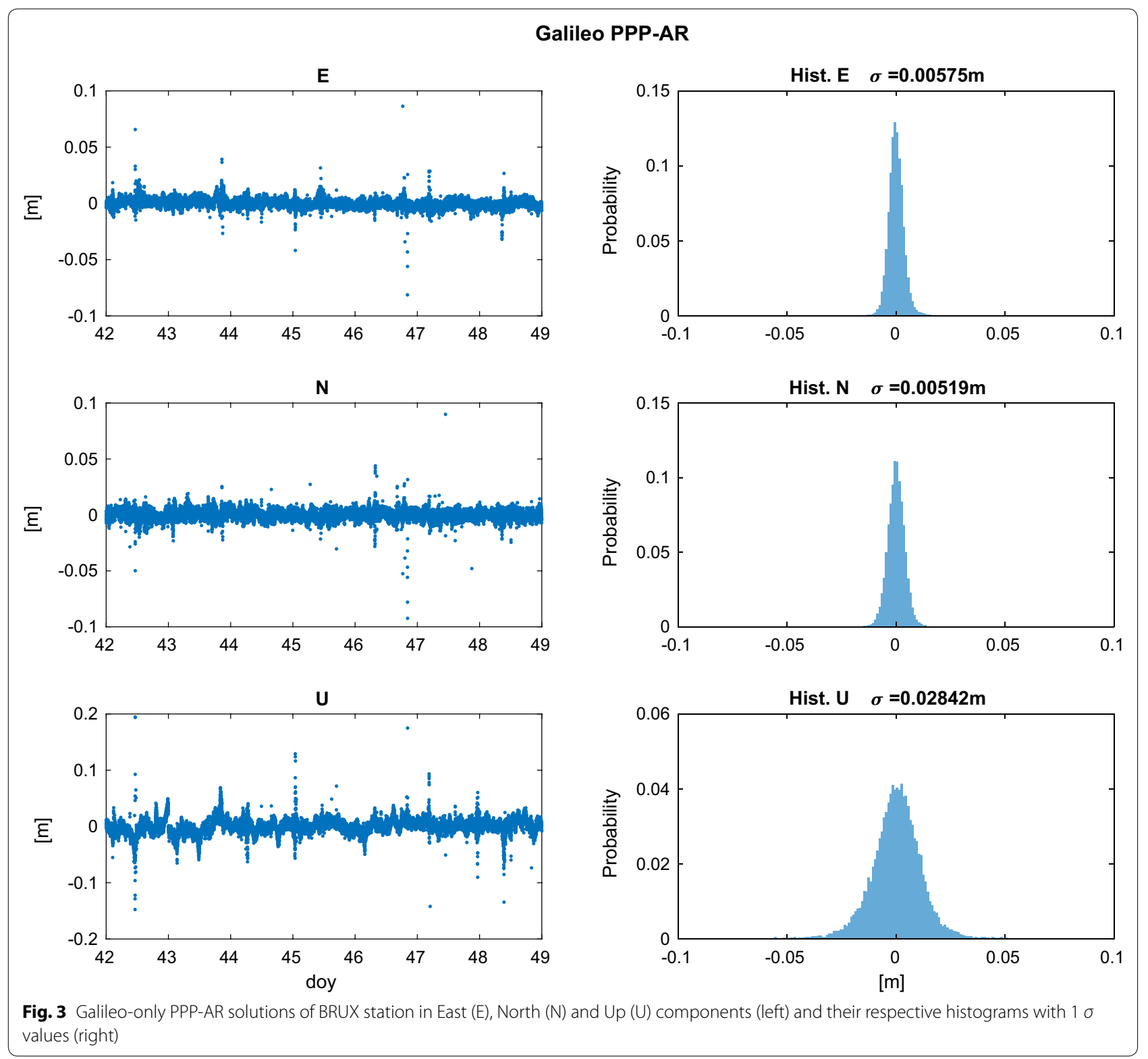

Figures 2 and 3 present a comparison between the float and fixed solutions for BRUX station. As it is shown, the precision is improved significantly from PPP to PPP-AR solutions.

\section{Summary, conclusions and perspectives}

With the appearance and the completion of new GNSS systems, it became clear that we move toward a multiGNSS era. However, it is also important to examine the performance of each GNSS system individually. Since the CNES/CLS AC is already providing orbit and clock products to enable ambiguity resolution for Galileo (Loyer et al. 2018), it is essential that these high-quality products be used for PPP and PPP-AR performance evaluation.
In this paper, we examined the performance of the Galileo-only PPP and PPP-AR solutions in post-processing kinematic mode. Repeatability results showed $10 \mathrm{~mm}$ for East, $7 \mathrm{~mm}$ for North and $33 \mathrm{~mm}$ for Up component when performing PPP solution. The quality of results increases when performing PPP-AR solution: $6 \mathrm{~mm}$ for East, $5 \mathrm{~mm}$ for North and $28 \mathrm{~mm}$ for Up component in the example of BRUX station.

Processing on other stations were also performed giving similar results (in the order of mm level). Results show that the method is applicable to any geodetic Galileo data receiver.

This is a first indication showing that Galileo-only solutions can reach unprecedented levels of precision that 
can be used for the most high-accuracy demanding postprocessing applications.

Taking all the above benefits into consideration, it seems obvious that efforts toward the PPP-real-time kinematic (RTK) with ambiguity resolution using Galileo will be the next future demand. There is a big anticipation from the GNSS community for the completion of the full Galileo constellation. One thing is clear: The Galileo system rests an important contribution to multi-GNSS processing.

\begin{abstract}
Abbreviations
PPP: precise point positioning; GNSS: global navigation satellite system; PPP-AR: PPP with ambiguity resolution; IGS: International GNSS Service; IRCS: integer recovery clocks; MGEX: multi-GNSS experiment; AC: analysis centers; IPPP: integer-PPP; MW: Melbourne-Wübbena; WL: wide-lane; WSB: wide-lane satellite bias; WRB: wide-lane receiver bias; RTK: real-time kinematic.
\end{abstract}

\section{Acknowledgements}

Not applicable.

\section{Authors' contributions}

GK and MG performed the processing. GK, FP and SL discussed and analyzed the data. GK and FP edited the article. All authors read and approved the final manuscript.

\section{Funding}

Not applicable.

\section{Availability of data and materials}

All data used in the present letter are available from the authors upon request.

\section{Competing interests}

The authors declare that they have no conflict of interest.

\section{Declarations}

Not applicable.

\section{Availability of data}

All data used in the present paper are available from the authors upon request.

\author{
Author details \\ ${ }^{1}$ Centre National d'Etudes Spatiales (CNES), 18 Avenue Edouard Belin, \\ 31400 Toulouse, France. ${ }^{2}$ Collecte Localisation Satellites (CLS), 8-10 rue \\ Hermès, 31520 Ramonville Saint Agne, France. ${ }^{3}$ Géosciences Environnement \\ Toulouse - Observatoire Midi-Pyrénées (GET-OMP/CNRS), 14 Avenue Edouard \\ Belin, 31400 Toulouse, France.
}

Received: 1 April 2019 Accepted: 29 June 2019

Published online: 12 July 2019

\section{References}

Blewitt G (1989) Carrier-phase ambiguity resolution for the global positioning system applied to baselines up to $2000 \mathrm{~km}$. J Geophys Res, 94:187-203. http://www.colorado.edu/ASEN/asen6090/blewitt.pdf

Dong D, Bock Y (1989) Global positioning system network analysis with phase ambiguity resolution applied to crustal deformation studies in California. J Geophys Res 94:3949-3966. https://doi.org/10.1029/JB094iB04p03949

Dow J, Neilan R, Rizos C (2009) The international GNSS Service in a changing landscape of global navigation satellite systems. J Geodesy 83:191-198. https://doi.org/10.1007/s00190-008-0300-3
Fund F, Perosanz F, Testut L, Loyer S (2013) An integer precise point positioning technique for sea surface observations using a GPS buoy. Adv Sp Res 51:1311-1322. https://doi.org/10.1016/j.asr.2012.09.028

Geng J, Meng X, Dodson A, Teferle F (2010) Integer ambiguity resolution in precise point positioning: method comparison. J Geodesy 84:569-581. https://doi.org/10.1007/s00190-010-0399-x

GSA (2019) Galileo system status_orbital and technical parameters. https:// www.gsc-europa.eu/system-status/orbital-and-technical-parameters

IGS (2011) International global navigation satellite systems service multi-GNSS experiment—call for participation. ftp://igs.org/pub/resource/pubs/ IGS\%20M-GEX\%20VF.pdf

Katsigianni G, Loyer S, Perosanz F, Mercier F (2018a) Improving Galileo orbit determination using zero-difference ambiguity resolution in a multi-GNSS processing. Wuhan, China

Katsigianni G, Loyer S, Perosanz F, Mercier F, Zajdel R, Sośnica K (2018) Improving Galileo orbit determination using zero-difference ambiguity fixing in a multi-GNSS processing. Adv Sp Res https://doi.org/10.1016/j. asr.2018.08.035

Kouba J (2009) A guide using the IGS products. https://kb.igs.org/hc/en-us/ articles/201271873-A-Guide-to-Using-the-IGS-Products

Laurichesse D, Mercier F, Berthias J, Broca P, Cerri L (2009) Integer ambiguity resolution on undifferenced GPS phase measurements and its application to PPP and satellite precise orbit determination. Navigation 2:135-149

Li X, Li X, Yuan Y, Zhang K, Zhang X, Wickert J (2018) Multi-GNSS phase delay estimation and PPP ambiguity resolution: GPS, BDS, GLONASS, Galileo. J Geodesy 92(6):579-608. https://doi.org/10.1007/s00190-017-1081-3

Loyer S, Perosanz F, Mercier F, Capdeville H, Marty J (2012) Zero-difference GPS ambiguity resolution at CNES-CLS IGS analysis center. J Geodesy 86:991-1003. https://doi.org/10.1007/s00190-012-0559-2

Loyer S, Perosanz F, Versini L, Katsigianni G, Mercier F, Mezerette A (2018) CNES/ CLS IGS analysis center: recent activities. Poster at IGS Workshop 2018. Wuhan, China

Melbourne W (1985) The case for ranging in GPS based geodetic system. In: 1st international symposium on precise positioning with the global positioning system. U.S. Department of Commerce, Rockville, MD, pp 373-386

Montenbruck O, Steigenberger P, Prange L, Deng Z, Zhao Q, Perosanz F, Schaer $S$ (2017) The multi-GNSS experiment (MGEX) of the international GNSS service (IGS)-achievements, prospects and challenges. Adv Sp Res 59(7):1671-1697. https://doi.org/10.1016/j.asr.2017.01.011

Montenbruck O, Hackel S, Jäggi A (2018) Precise orbit determination of the Sentinel-3A altimetry satellite using ambiguity-fixed GPS carrier phase observations. J Geodesy 92(7):711-726. https://doi.org/10.1007/s0019 0-017-1090-2

Perosanz F, Loyer S, Katsigianni G, Mercier F, Versini L (2018) Galileo un-differenced integer products: method, results and perspectives: presentation at IGS workshop 2018. Wuhan, China. http://www.igs.org/w18/7797

Petit G, Kanj A, Loyer S, Delporte J, Mercier F, Perosanz F (2015) 1 × 10-16 frequency transfer by GPS PPP with integer ambiguity resolution. Metrologia 52:301-309. https://doi.org/10.1088/0026-1394/52/2/301

Wübbena G (1985) Software developments for geodetic positioning with GPS using TI-4100 code and carrier measurements. In: 1st international symposium on precise positioning with the global positioning system. U.S. Department of Commerce, Rockville, MD, pp 403-412

Xia F, Ye S, Xia P, Zhao L, Jian N, Chen D, Hu G (2018) Assessing the latest performance of Galileo-only PPP and the contribution of Galileo to multi-GNSS PPP. Sp Res, Adv. https://doi.org/10.1016/j.asr.2018.06.008

Zumberge J, Heflin M, Jefferson D, Watkins M, Webb F (1997) Precise point positioning for the efficient and robust analysis of GPS data from large networks. J Geophys Res 102(B3):5005-5017

\section{Publisher's Note}

Springer Nature remains neutral with regard to jurisdictional claims in published maps and institutional affiliations. 